\title{
Prophylactic Tibial Stem Fixation in the Obese: Comparative Early Results in Primary Total Knee Arthroplasty
}

Joshua T. Steere, $\mathrm{MD}^{1}$, Michael C. Sobieraj, $\mathrm{MD}^{1}$, Christopher J. DeFrancesco, BS ${ }^{2}$, Craig L. Israelite, $\mathrm{MD}^{1}$, Charles L. Nelson, $\mathrm{MD}^{1}$, and Atul F. Kamath, $\mathrm{MD}^{1}$

${ }^{1}$ Department of Orthopedic Surgery, Pennsylvania Hospital, University of Pennsylvania Health System, Philadelphia, PA; ${ }^{2}$ Perelman School of Medicine, University of Pennsylvania, Philadelphia, PA, USA

Purpose: Obesity is a risk factor for aseptic loosening after total knee arthroplasty (TKA). Prophylactic use of tibial stems may enhance tibial fixation in obese patients. The aim of this study was to determine whether a tibial stem extension decreases rates of early failure in obese patients.

Materials and Methods: This study included 178 consecutive primary TKAs (143 patients) with a body mass index $\geq 35 \mathrm{~kg} / \mathrm{m}^{2}$. Fifty TKAs were performed with the use of a $30 \mathrm{~mm}$ tibial stem extension, and 128 TKAs were performed with a standard tibial component. Patients with twoyear clinical follow-up were included. The primary outcome was revision for aseptic loosening. Secondary outcomes were all-cause revision and radiolucent lines (RLLs) on radiographs.

Results: Average follow-up was 34 months (range, 24 to 46 months). No failures for aseptic loosening occurred. The occurrence of secondary procedures was not significantly different between groups. Quantification of RLLs revealed no difference between groups.

Conclusions: At early follow-up, no difference was measured in revision rates, need for subsequent procedures, or RLLs between groups.

Keywords: Knee, Obesity, Arthroplasty, Stem

\section{Introduction}

Obesity is an epidemic which has been associated with increased complications and lower outcome scores after total knee arthroplasty (TKA) $)^{1-5)}$. The World Health Organization defines obesity as a body mass index (BMI) greater than $30 \mathrm{~kg} / \mathrm{m}^{2}$, and over one-third of adults in the United States are estimated to be obese ${ }^{6,7)}$. The number of obese patients undergoing total joint arthroplasty has subsequently increased in recent decades ${ }^{5}$.

Received March 29, 2018; Revised May 26, 2018;

Accepted July 11, 2018

Correspondence to: Atul F. Kamath, MD

Department of Orthopedic Surgery, Pennsylvania Hospital, 800 Spruce Street, 8th Floor Preston, Philadelphia, PA 19107, USA

Tel: +1-215-687-8169, Fax: +1-215-829-5367

E-mail: akamath@post.harvard.edu

This is an Open Access article distributed under the terms of the Creative Commons Attribution Non-Commercial License (http://creativecommons.org/licenses/by-nc/4.0/) which permits unrestricted non-commercial use, distribution, and reproduction in any medium, provided the original work is properly cited.
Aseptic loosening is a leading cause for revision TKA in the United States, contributing to $20 \%-40 \%$ of all-component revisions for $\mathrm{TKA}^{8,9)}$. Aseptic loosening was found to be the second most common cause for early failure $(<2$ years) and the most common cause of late failure ( $>2$ years $)^{9)}$. Obesity has recently been shown to increase this risk for aseptic loosening after primary TKA. Patients with BMI $\geq 35 \mathrm{~kg} / \mathrm{m}^{2}$ were twice more likely to have aseptic loosening at 5- and 15-year follow-up than patients with $\mathrm{BMI}<35 \mathrm{~kg} / \mathrm{m}^{21)}$. Weight gain after index TKA has similarly been shown to increase early failure from aseptic loosening ${ }^{2)}$.

Tibial stem extensions have been used to enhance proximal tibial fixation for a number of indications in primary TKA, and the use of a tibial stem extension have been described as a potential strategy to reduce mechanical failure in obese patients after TKA $^{1,10,11)}$. Proximal tibia stress is affected by both body weight and tibial component design ${ }^{10-12)}$. Increased proximal tibia stress due to body weight and component design have been associated with mechanical failure ${ }^{9,11,13)}$. Tibial component design, such as a larger surface area or use of a stem extension, can theoretically 
help to dissipate these stresses by distributing them over a greater area.

This study is a short-term retrospective cohort analysis of two groups of patients with BMI $\geq 35 \mathrm{~kg} / \mathrm{m}^{2}$ who underwent primary TKA either with standard tibial components or with prophylactic short tibial stem extensions. The primary outcome measure was mechanical failure due to aseptic loosening. Secondary outcome measures were secondary procedures for any cause and quantification of radiolucent lines (RLLs).

\section{Materials and Methods}

After Institutional Review Board approval, the electronic medical record was reviewed to identify patients who underwent primary TKA during a single year (2013-2014) by two surgeons who specialize in TKA. Patients with $\mathrm{BMI} \geq 35 \mathrm{~kg} / \mathrm{m}^{2}$ at the time of surgery were included in the study. This cutoff was used because it is the same cutoff that was used in a recent and relevant analysis ${ }^{11}$. Radiographs were reviewed to determine whether a short tibial stem extension was used, and operative reports were reviewed for each case to determine the indication for use of a stem extension. Stems used prophylactically for obesity were included. Tibial stems used for any other indication were excluded. During this time period, a stem extension was used prophylactically in obese patients at the discretion of the surgeon and after conversation with the patient. Only after the study period did it become standard practice at this institution to use a short tibial
Table 1. Demographics

\begin{tabular}{lccc}
\hline \multicolumn{1}{c}{ Characteristic } & Stemmed & Standard & p-value \\
\hline Total knee arthroplasty & 50 & 128 & \\
Age (yr) & $61 \pm 8.8$ & $62 \pm 8.7$ & 0.49 \\
Female & $43(86)$ & $102(79)$ & 0.33 \\
Right side & $24(48)$ & $67(52)$ & 0.60 \\
Smaller size tibial component ${ }^{\mathrm{a}}$ & $38(76)$ & $77(60)$ & 0.047 \\
Time to follow-up (mo) & $30 \pm 3.8$ & $34 \pm 5.2$ & $<0.001$ \\
Body mass index (kg/m $\left.{ }^{2}\right)$ & $44.4 \pm 6.1$ & $39.8 \pm 4.1$ & $<0.001$ \\
35-39 (WHO class II) & $9(18)$ & $70(55)$ & \\
$\geq 40$ (WHO class III) & $41(82)$ & $58(45)$ & \\
$40-44$ & 22 & 31 & \\
$45-49$ & 12 & 15 & \\
50-54 & 3 & 2 & \\
55-60 & 4 & 0 & \\
Rheumatoid arthritis & 0 & $4(3)$ & 0.26 \\
Tobacco use & & & \\
Active & $4(8)$ & $15(12)$ & 0.59 \\
Former & $13(26)$ & $43(34)$ & 0.37 \\
Osteopenia or osteoporosis & $2(4)$ & $10(8)$ & 0.29 \\
Diabetes mellitus & $16(32)$ & $34(27)$ & 0.47 \\
\hline
\end{tabular}

Values are presented as mean \pm standard deviation or number (\%).

WHO: World Health Organization.

${ }^{a)}$ Defined as lower half of offered manufactured sizes (NexGen size, 1-4; Persona size, A-D).

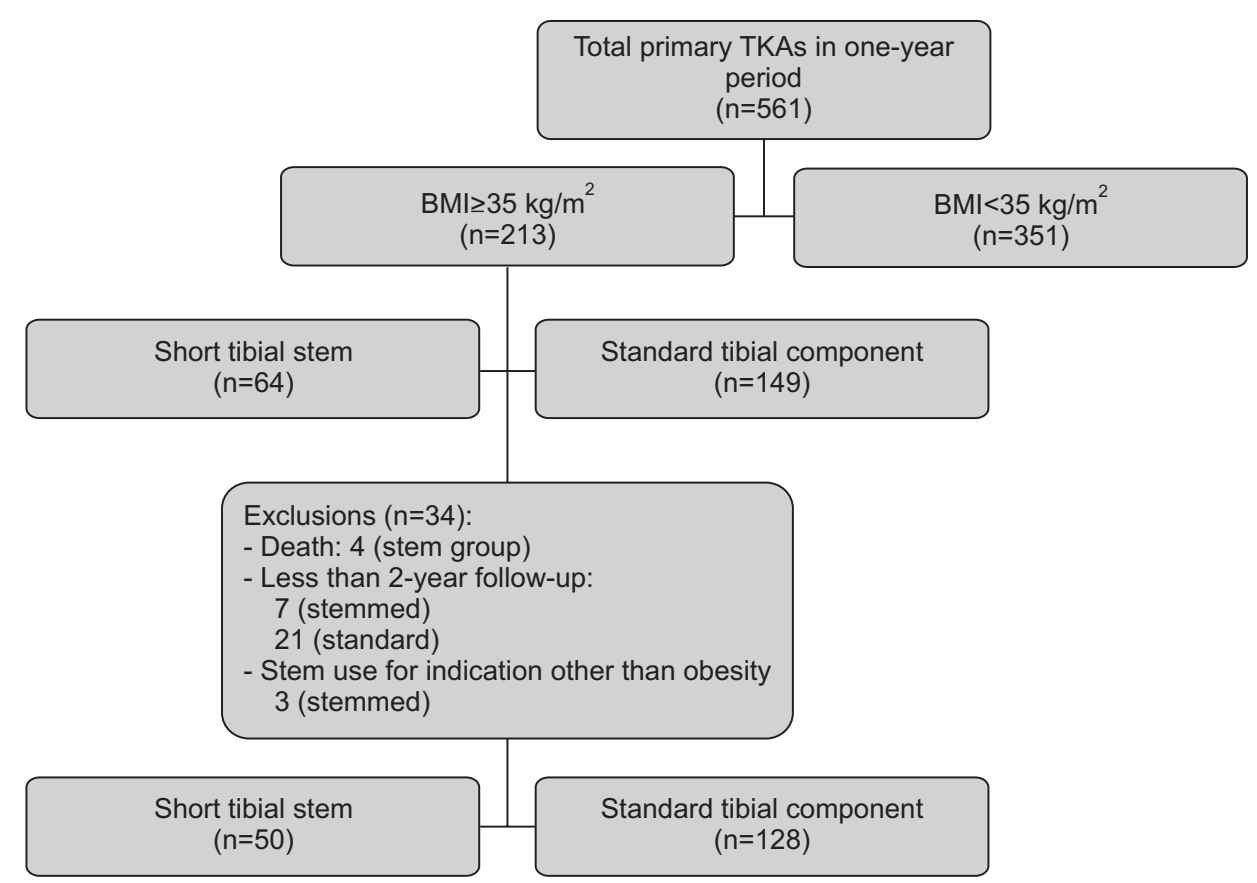

Fig. 1. Study design. TKA: total knee arthroplasty, BMI: body mass index. 
stem extension in patients with BMI $\geq 35 \mathrm{~kg} / \mathrm{m}^{2}$.

Patients were excluded if the stem extension was used for any indication other than obesity, such as conversion arthroplasty, significant hardware removal, or constrained articular geometry. Patients who underwent conversion from unicompartmental knee arthroplasty to TKA were excluded. Patients without an orthopedic follow-up visit two years or longer after index surgery were contacted via telephone or letter to determine if they had revision surgery or subsequent procedures after index TKA. Any patient who was unreachable was excluded.

Fig. 1 is a patient flow diagram showing that final comparison groups included 42 patients (50 TKAs) with short tibial stems and 101 patients (128 TKAs) with standard tibial components. Key demographic data are presented in Table 1.

Patients underwent posterior-stabilized TKA with either NexGen Legacy or Persona components (Zimmer Inc., Warsaw, IN, USA) and cemented femoral and modular metal-backed tibial trays. Patients in the stemmed group received a $30 \mathrm{~mm}$ short

Table 2. Implant Design

\begin{tabular}{lcc}
\hline \multicolumn{1}{c}{ Tibial component } & Stemmed (\%) & Standard (\%) \\
\hline Zimmer NexGen Legacy & $49(98)$ & $53^{\text {a) }}(41)$ \\
Zimmer Persona & $1(2)$ & $73(57)$ \\
Smith \& Nephew Genesis II & 0 & $2^{\text {b) }}(1)$ \\
\hline
\end{tabular}

All implants were cemented metal-backed posterior stabilized tibial components except as noted:

a) Includes one uncemented trabecular metal monoblock tibial component.

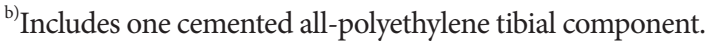

tibial stem extension (Zimmer Inc.). In the standard tibia group, two patients underwent posterior-stabilized TKA with Smith \& Nephew Genesis II (Smith \& Nephew Inc., Memphis, TN, USA) cemented components due to reported metal allergies. One of these patients had a cemented all-polyethylene tibial component. One patient in the standard tibia group was treated with a Zimmer NexGen Legacy uncemented trabecular metal modular tibial tray. Implant records were collected from the operative reports and are listed in Table 2.

Anteroposterior (AP) and lateral knee radiographs obtained greater than two years after index procedure were reviewed by two independent observers not involved in the surgeries (Fig. 2). The Knee Society total knee arthroplasty roentgenographic evaluation scoring system (KSRES) score was assigned based on the cumulative number of RLLs on the AP and lateral films ${ }^{14}$ (Fig. 3). The KSRES scores were rated as $4 \mathrm{~mm}$ or less, $5-9 \mathrm{~mm}$, and $10 \mathrm{~mm}$ or greater. The radiographs were also assigned a percentage based score (PBS) according to a recently described technique ${ }^{15)}$. The extent of RLLs on AP and lateral views was assigned a percentage involvement with respect to the total tibial surface. PBS values were placed into three groups: $<10 \%, 11 \%-25 \%$, and $>25 \%$. Kappa values were used to measure interobserver reliability for both KRES and PBS grouping.

Statistical analysis included Fisher exact tests for categorical variables and 2-sample Student $t$-tests for continuous variables. All tests were two-tailed, and p-values were considered significant at 0.05 . Continuous variables were reported as mean and standard deviation (SD), and categorical variables as percentage.
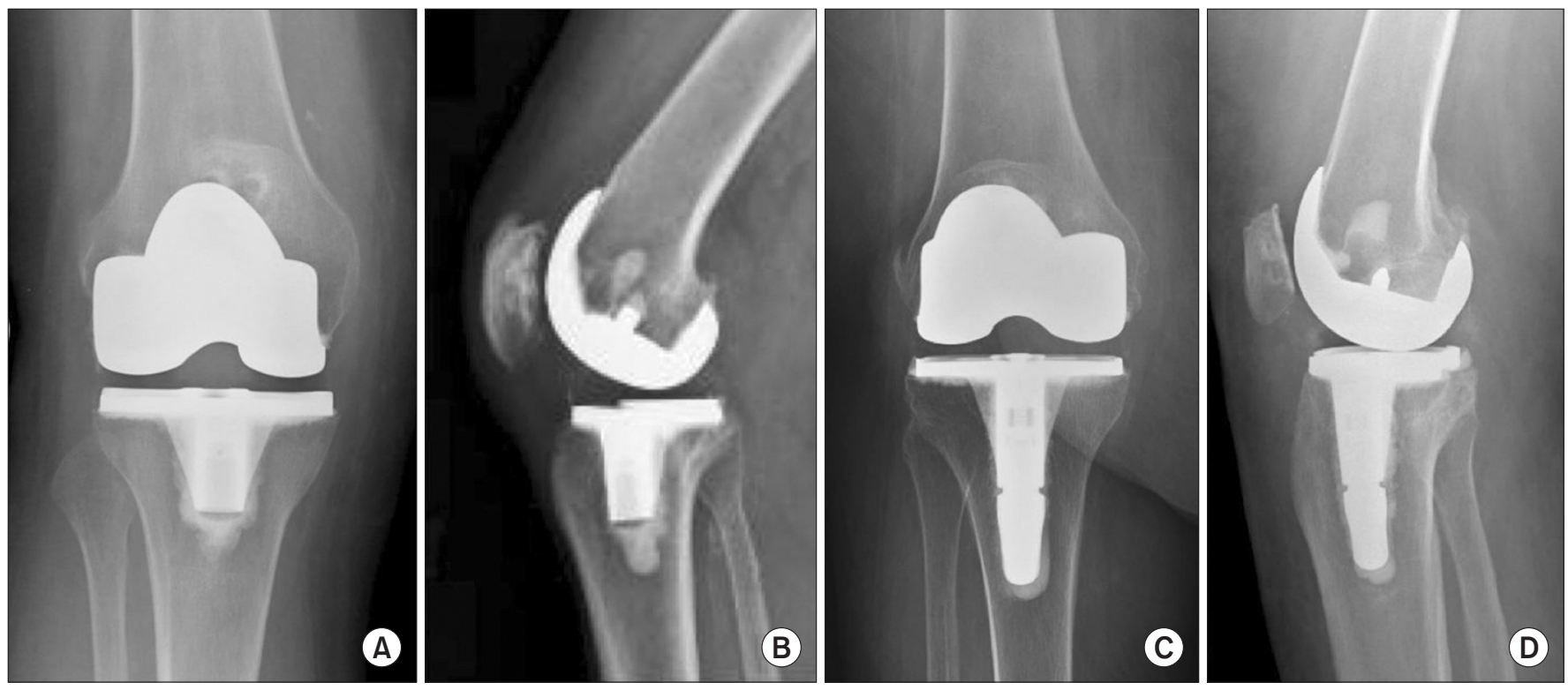

Fig. 2. Radiographs with standard tibial component (A, B) and short stem extension (C, D). 

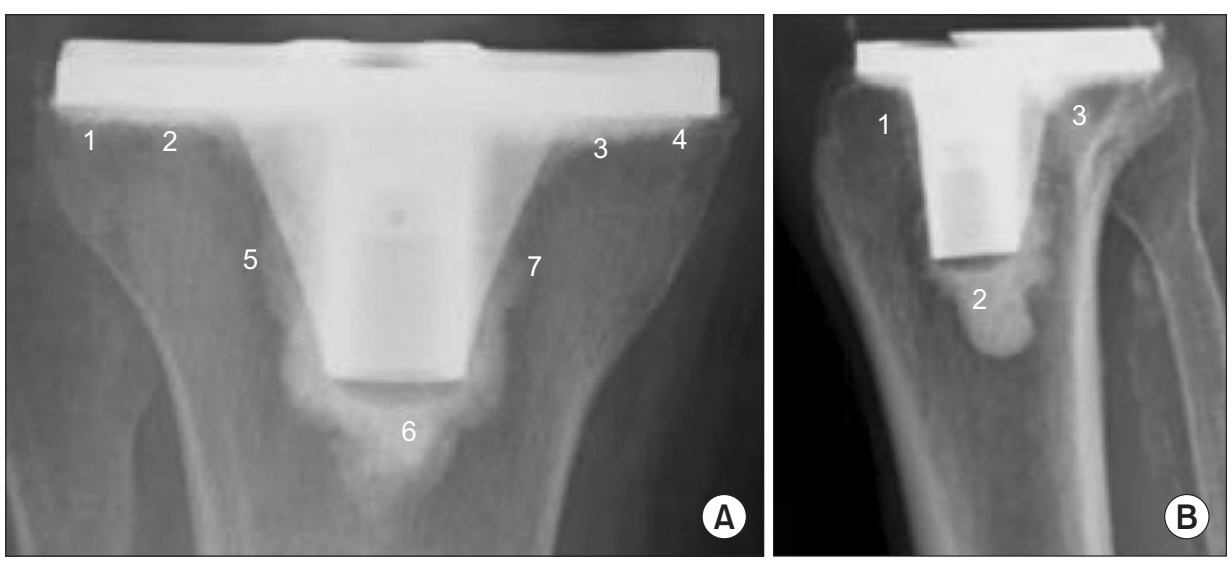

Fig. 3. Tibial zones for the Knee Society total knee arthroplasty roentgenographic evaluation scoring system calculation based on Ewald ${ }^{14)}$ (1989) and Chalmers et al. ${ }^{15)}$ (2017). The sum of the radiolucent lines for each zone was calculated on the anteroposterior (A) and lateral (B) radiographs.

Table 3. Complications Requiring Secondary Procedures

\begin{tabular}{lccccc}
\hline \multirow{2}{*}{ Characteristic } & \multicolumn{2}{c}{$\begin{array}{c}\text { BMI } \geq 35 \mathrm{~kg} / \mathrm{m}^{2} \\
(\mathrm{p}=1.00)\end{array}$} & & \multicolumn{2}{c}{$\begin{array}{c}\text { BMI } \geq 40 \mathrm{~kg} / \mathrm{m}^{2} \\
(\mathrm{p}=0.17)\end{array}$} \\
\cline { 2 - 3 } \cline { 5 - 6 } & Stemmed & Standard & & Stemmed & Standard \\
\hline Total $^{\text {a) }}$ & $2(4 \%)$ & $6(4.7 \%)$ & & $2(4 \%)$ & 0 \\
Aseptic loosening & 0 & 0 & & 0 & 0 \\
Patella dislocation & 1 & 0 & & 1 & 0 \\
Instability & 1 & 0 & & 1 & 0 \\
Stiffness requiring & 0 & 4 & & 0 & 0 \\
$\quad$ manipulation & & & & & 0 \\
Wound Complication & 0 & 1 & & 0 & 0 \\
Infection & 0 & 1 & & 0 & 0 \\
Periprosthetic fracture & 0 & 0 & & 0 & 0 \\
\hline
\end{tabular}

BMI: body mass index.

${ }^{\mathrm{a})} \mathrm{p}=1.00$.

\section{Results}

The average age of all patients was 62 years (range, 40 to 86; SD, 8.7). The average BMI was greater in the stemmed cohort than the standard cohort ( 44.4 vs. $39.8, \mathrm{p}<0.001$; confidence interval, -6.1 to -3.0$)$. The average clinical follow-up was 32 months (range, 24 to 46 months; SD, 5.2), and average radiographic follow-up was 32 months (range, 24 to 46 months; SD, 5.6).

No patients in either group underwent revision for aseptic loosening, the primary outcome measure. As shown in Table 3, no difference in secondary procedures was measured between groups. Notably, four patients underwent manipulation under anesthesia (MUA) 6-10 weeks after index procedure for stiffness. Indication for MUA was flexion range of motion less than 90 degrees within 6-8 weeks of index surgery. Subgroup analysis of patients with $\mathrm{BMI} \geq 40 \mathrm{~kg} / \mathrm{m}^{2}$ did not show a difference in complications between groups.
Table 4. Measurement of Radiolucent Lines about Tibial Component

\begin{tabular}{lccccc}
\hline \multirow{2}{*}{ Parameter } & \multicolumn{2}{c}{$\mathrm{BMI} \geq 35 \mathrm{~kg} / \mathrm{m}^{2}(\mathrm{p}=0.80)^{\mathrm{a})}$} & & \multicolumn{2}{c}{$\left.\mathrm{BMI} \geq 40 \mathrm{~kg} / \mathrm{m}^{2}(\mathrm{p}=0.337)^{\mathrm{a}}\right)$} \\
\cline { 2 - 3 } \cline { 5 - 6 } & Stemmed (\%) & Standard (\%) & & Stemmed (\%) & Standard (\%) \\
\hline$\leq 4 \mathrm{~mm}$ & $31(86)$ & $70(84)$ & & $25(89)$ & $31(79)$ \\
$4-9 \mathrm{~mm}$ & $5(14)$ & $13(16)$ & & $3(11)$ & $8(21)$ \\
$>10 \mathrm{~mm}$ & 0 & 0 & 0 & 0 \\
Total & 36 & 83 & & 28 & 39 \\
\hline
\end{tabular}

Radiolucent lines were measured on anteroposterior and lateral films. BMI: body mass index.

${ }^{\text {a) }}$ Fisher exact test.

Table 5. Percentage-Based Measurement of Radiolucent Lines about Tibial Component

\begin{tabular}{lccccc}
\hline \multirow{2}{*}{ Parameter } & \multicolumn{2}{c}{$\mathrm{BMI} \geq 35 \mathrm{~kg} / \mathrm{m}^{2}(\mathrm{p}=0.11)^{\mathrm{a})}$} & & \multicolumn{2}{c}{$\left.\mathrm{BMI} \geq 40 \mathrm{~kg} / \mathrm{m}^{2}(\mathrm{p}=0.244)^{\mathrm{a}}\right)$} \\
\cline { 2 - 3 } \cline { 5 - 6 } \cline { 5 - 6 } & \multicolumn{2}{c}{ Stemmed (\%) Standard (\%) } & & Stemmed (\%) & Standard (\%) \\
\hline$\leq 10 \%$ & $13(36)$ & $32(39)$ & & $10(36)$ & $14(36)$ \\
$11 \%-24 \%$ & $23(64)$ & $39(47)$ & & $18(64)$ & $21(54)$ \\
$>25 \%$ & 0 & $12(14)$ & & 0 & $4(10)$ \\
Total & 36 & 83 & & 28 & 39 \\
\hline
\end{tabular}

Percentage was measured on anteroposterior and lateral films. BMI: body mass index.

${ }^{\text {a) }}$ Fisher exact test.

Radiographs were available for 36 TKAs (72\%) in the stemmed group and 83 TKAs (64\%) in the standard group more than 2 years after index surgery. Analysis of knee radiographs for RLLs failed to reveal any difference between groups (Table 4). There was also no apparent difference between groups in KSRES. Table 5 shows that there was no apparent difference between groups in PBS grouping. Kappa values for KSRES and PBS scoring were 0.32 and 0.22 , respectively. Subgroup analysis of patients with BMI $\geq 40 \mathrm{~kg} / \mathrm{m}^{2}$ did not show a difference in RLLs between groups. 


\section{Discussion}

This short-term retrospective cohort study describes the use of prophylactic short tibial stem extensions in primary TKA in patients with BMI $\geq 35 \mathrm{~kg} / \mathrm{m}^{2}$. To our knowledge, this is the first comparison of TKA with prophylactic short tibial stems versus TKA with standard tibial components in obese patients. This short-term follow-up (2 years of clinical and radiographic followup) study revealed no instances of aseptic loosening in either group.

Body weight and obesity have been shown to be risk factors for aseptic loosening. Lim et al. ${ }^{2)}$ reported that weight gain after primary TKA increased the rate of both early ( $<5$ years) and late (>10 years) failure due to aseptic loosening. Abdel et al. ${ }^{1)}$ reported higher rates of aseptic loosening in obese patients after primary TKA. Their sample of 5,088 TKAs showed that patients with BMI $\geq 35 \mathrm{~kg} / \mathrm{m}^{2}$ were twice as likely to undergo revision for aseptic loosening at five years (1.23\% vs. $0.49 \%)$ and at fifteen years $(4.27 \%$ vs. $2.16 \%)$. All cases of aseptic loosening occurred in patients without supplemental tibial stem extensions, and the authors suggested additional tibial fixation may be warranted in these patients.

Attention has been drawn to the way both body weight and tibial component design influence proximal tibial stresses and mechanical failure in obese patients. Because the length and width of the tibial tray is limited by the bony anatomy in TKA, many obese patients cannot receive a commensurately larger tibial tray. In this patient population, for example, $65 \%$ of patients with BMI $>35 \mathrm{~kg} / \mathrm{m}^{2}$ had tibial components in the smaller half of sizes offered by the manufacturer. Fehring et al. ${ }^{10)}$ similarly found that $77 \%$ of obese patients with aseptic loosening had tibial components in the smaller half of manufactured sizes. The smaller surface area causes more concentrated stress on the implant and adjacent metaphyseal tibial bone, which may be directly related to premature failure of the tibial component.

Recent studies have measured proximal tibial stress in obese patients. Both Fehring et al. ${ }^{10)}$ and Berend et al. ${ }^{12)}$ measured tibial component stress as a function of patient weight and tibial component size. Fehring et al. ${ }^{10}$ calculated tibial stress in 35 cases of tibial component varus collapse. Average BMI among these patients was $40.5 \mathrm{~kg} / \mathrm{m}^{2}$. Mean time to failure was 7.2 years, and average tibial stress was 350,000 pascals. None of these patients had tibial stems. Berend et al. ${ }^{12)}$ analyzed aseptic loosening among 6,548 TKAs and calculated proximal tibia stress in both failures and non-failures. The overall rate of aseptic loosening was $0.8 \%$ at a mean of 3.1 years. Patients with greater proximal tibia stress
(>360,000 pascals) had significantly higher rates of aseptic loosening than those with lower proximal tibia stress, even in wellaligned knees.

Reducing proximal tibial stress can be achieved through preoperative weight loss, use of a larger tibia component, and use of a tibial stem extension. Because tibial component size is limited by anatomy, efforts to reduce tibial stress rely primarily on preoperative weight loss and use of tibial stem extensions. The use of a tibial stem has been shown biomechanically to reduce micromotion and subsidence compared to standard tibial components ${ }^{15)}$. Similarly, Ries et al. ${ }^{13)}$ reported a higher failure rate with the use of a short-keeled tibial component. These authors compared a series of 80 patients with short-keeled tibial components to 80 patients with standard components and noted a higher rate of early failure with short-keeled components at a mean of 13 months.

The use of long tibial stems has been studied in obese patients as a means of improving tibial fixation in TKA. Parratte et al. ${ }^{11)}$ conducted a prospective study in which 120 patients with BMI $\geq 30 \mathrm{~kg} / \mathrm{m}^{2}$ were randomized to receive a $100 \mathrm{~mm}$ length tibial stem extension or standard tibial components. The study was concluded after two years, and the authors found no difference in mechanical complications. The authors acknowledged the short duration of follow-up. They also cautioned against routine use of long stems in light of their findings such as increased difficulty instrumenting and revising long-stemmed implants. Compared to long stems, the potential benefit of short stems (e.g., $30 \mathrm{~mm}$ ) would be the need for less bone removal and easier revision, if needed. Also, issues of stem conflict within the proximal metadiaphysis of the tibia may be mitigated by a shorter length of stem. One potential downside to using a tibial stem (long or short) is cost: the average price of a short stem is approximately $\$ 950$ at this institution.

An adult with a BMI $\geq 30 \mathrm{~kg} / \mathrm{m}^{2}$ is considered obese. In this study, only patients with $\mathrm{BMI} \geq 35 \mathrm{~kg} / \mathrm{m}^{2}$ were enrolled. The reason is that a relevant study by Abdel et al. ${ }^{1)}$ used cutoff of BMI $>35 \mathrm{~kg} / \mathrm{m}^{2}$. The other reason is that if BMI directly increases the risk of aseptic loosening, and if the use of tibial stems were to reduce this risk as hypothesized, then enrolling patients with higher BMI may increase any measured difference between groups.

Limitations of this study include the small sample size. Complications may have been missed in those patients lost to follow-up. The duration of follow-up may also be too short to demonstrate a difference in aseptic loosening, which may explain why no revisions for aseptic loosening were observed. One of the major limitations of this study is that the use of tibial stems was not randomized between groups. Instead, patients were treated with 
a stem extension at the discretion of the surgeon. When stem extensions were used, it was more often in patients with greater BMI. Theoretically, this selection bias could have resulted in less failures in these more at-risk patients than if they had been randomly assigned to receive standard components. While this was the intended clinical benefit, it means the negative findings should be interpreted cautiously. More data is also needed to examine the influence of increasing obesity severity (e.g., super obese BMI category) on the utility and effectiveness of stemmed fixation. Finally, radiographs used in the measurement of RLLs were not performed with fluoroscopic guidance but rather with routine postoperative clinic films. Fluoroscopic guidance has been shown to improve the accuracy of RLL measurements on knee radiographs ${ }^{16-18)}$.

\section{Conclusions}

This short-term retrospective cohort analysis presents two groups of patients with $\mathrm{BMI} \geq 35 \mathrm{~kg} / \mathrm{m}^{2}$ who underwent primary TKA either with standard tibial components or with prophylactic short tibial stem extensions. While short tibial stem extensions may play a role in the future in reducing the risk of aseptic loosening in obese patients, this study did not reveal a statistically significant relationship between the use of short stems and revision rate, need for subsequent procedures, or RLLs. More data is needed to characterize obese patients most at risk of tibial failure based on other factors such as age and activity level. No instances of mechanical failure were recorded among the patients after early follow-up, but longer-term follow-up will be needed to continue to measure implant longevity and to examine the effect of tibial stem fixation on aseptic loosening rates in the obese.

\section{Conflict of Interest}

No potential conflict of interest relevant to this article was reported.

\section{References}

1. Abdel MP, Bonadurer GF 3rd, Jennings MT, Hanssen AD. Increased aseptic tibial failures in patients with a BMI $\geq 35$ and well-aligned total knee arthroplasties. J Arthroplasty. 2015;30:2181-4.

2. Lim CT, Goodman SB, Huddleston JI 3rd, Harris AHS, Bhowmick S, Maloney WJ, Amanatullah DF. Weight gain after primary total knee arthroplasty is associated with accel- erated time to revision for aseptic loosening. J Arthroplasty. 2017;32:2167-70.

3. Lubbeke A, Zingg M, Vu D, Miozzari HH, Christofilopoulos P, Uckay I, Harbarth S, Hoffmeyer P. Body mass and weight thresholds for increased prosthetic joint infection rates after primary total joint arthroplasty. Acta Orthop. 2016;87:132-8.

4. Samson AJ, Mercer GE, Campbell DG. Total knee replacement in the morbidly obese: a literature review. ANZ J Surg. 2010;80:595-9.

5. Odum SM, Springer BD, Dennos AC, Fehring TK. National obesity trends in total knee arthroplasty. J Arthroplasty. 2013;28(8 Suppl):148-51.

6. Ogden CL, Carroll MD, Kit BK, Flegal KM. Prevalence of childhood and adult obesity in the United States, 2011-2012. JAMA. 2014;311:806-14.

7. World Health Organization. Obesity: preventing and managing the global epidemic. Report of a WHO consultation (WHO technical report series no. 894) [Internet]. Geneva: World Health Organization; 2000 [cited 2018 Aug 20]. Available from: http://www.who.int/nutrition/publications/ obesity/WHO_TRS_894/en/.

8. Bozic KJ, Kamath AF, Ong K, Lau E, Kurtz S, Chan V, Vail TP, Rubash H, Berry DJ. Comparative epidemiology of revision arthroplasty: failed THA poses greater clinical and economic burdens than failed TKA. Clin Orthop Relat Res. 2015;473:2131-8.

9. Sharkey PF, Lichstein PM, Shen C, Tokarski AT, Parvizi J. Why are total knee arthroplasties failing today: has anything changed after 10 years? J Arthroplasty. 2014;29:1774-8.

10. Fehring TK, Fehring KA, Anderson LA, Otero JE, Springer BD. Catastrophic varus collapse of the tibia in obese total knee arthroplasty. J Arthroplasty. 2017;32:1625-9.

11. Parratte S, Ollivier M, Lunebourg A, Verdier N, Argenson JN. Do Stemmed tibial components in total knee arthroplasty improve outcomes in patients with obesity? Clin Orthop Relat Res. 2017;475:137-45.

12. Berend ME, Ritter MA, Hyldahl HC, Meding JB, Redelman R. Implant migration and failure in total knee arthroplasty is related to body mass index and tibial component size. J Arthroplasty. 2008;23(6 Suppl 1):104-9.

13. Ries C, Heinichen M, Dietrich F, Jakubowitz E, Sobau C, Heisel C. Short-keeled cemented tibial components show an increased risk for aseptic loosening. Clin Orthop Relat Res. 2013;471:1008-13.

14. Ewald FC. The Knee Society total knee arthroplasty roentgenographic evaluation and scoring system. Clin Orthop 
Relat Res. 1989;(248):9-12.

15. Chalmers BP, Sculco PK, Fehring KA, Trousdale RT, Taunton MJ. A novel percentage-based system for determining aseptic loosening of total knee arthroplasty tibial components. J Arthroplasty. 2017;32:2274-8.

16. Ecker ML, Lotke PA, Windsor RE, Cella JP. Long-term results after total condylar knee arthroplasty. Significance of radiolucent lines. Clin Orthop Relat Res. 1987;(216):151-8.
17. Bach CM, Biedermann R, Goebel G, Mayer E, Rachbauer F. Reproducible assessment of radiolucent lines in total knee arthroplasty. Clin Orthop Relat Res. 2005;(434):183-8.

18. Seong SC, Kim JK, Park SE, Jang JD, Cho HC, Kim SR, Lee MC, Lim CK. Clinical and radiological results of total knee arthroplasty with a system of asymmetric tibial tray. J Korean Knee Soc. 2000;12:151-8. 